\title{
Segmentation of the Aleutian plate boundary derived from stress direction estimates based on fault plane solutions
}

\author{
Zhong Lu and Max Wyss \\ Geophysical Institute, University of Alaska, Fairbanks
}

\begin{abstract}
We propose a new method to investigate stress homogeneity along plate boundaries based on the cumulative misfit of individual fault plane solutions, calculated using assumed stress tensors. Using this method, some segments of faults can be defined, without the time-consuming inversions for stress directions from earthquake fault plane solutions. We assume that the misfits are relatively constant within segments of uniform stress orientation but that they change abruptly at boundaries of segments. This assumption is supported by the pattern of misfits observed for about 400 earthquakes located along the Aleutian subduction zone from $170^{\circ} \mathrm{E}$ to $145^{\circ} \mathrm{W}$, which occurred between 1964 and 1993 . The efficacy of the approach is confirmed by stress inversion analysis of moving windows. The cumulative misfit as a function of strike along the Aleutian arc shows there are five first-order boundaries where the stress directions change significantly. The first one is near $177.5^{\circ} \mathrm{E}$, which corresponds to the northward projection of the Rat fracture zone. The second one falls on the Adak fracture zone. The third is near the locus where the Amlia fracture zone intersects the trench. The fourth lies on the easternmost end of the 1957 aftershock zone. The last is located where the two major asperities of the 1964 rupture are separated. The segmentation boundaries found in our analysis may be controlled by the fracture zones in the subducted plate. This observation may be interpreted as due to decoupling within the underthrusting plate along the zones of weakness (the fracture zones) across which stress may not be transmitted fully. The boundaries defined by our method may also be related to the asperity and aftershock distributions of great earthquakes. The focal mechanism data in the segments defined as stress-homogeneous by our method are then used to invert for the principal stress orientations by employing the Focal Mechanism Stress Inversion (FMSI) computer programs of Gephart. We find that the stress directions within these segments are different from each other, where they can be defined well, and the average misfits in these volumes are very small $\left(2.8^{\circ}\right.$ and $\left.5.5^{\circ}\right)$. The method is not robust enough to detect all the stress segmentation boundaries based on only one reference stress tensor. Analyses with different reference stress models help to define most or all the stress segmentation boundaries.
\end{abstract}

\section{Introduction}

The seismological evidence for the segmentation of the Aleutian arc, which has a history of rupturing in great earthquakes, is based on the distribution of the aftershock zones of these ruptures. The most recent sequence, beginning in $1938(M w=8.2)$, ruptured almost the entire Aleutian arc (Figure 1) in $1957(M w=8.6)$, $1964(M w=9.2)$, and $1965(M w=8.7)$. The segments of the arc which have apparently not ruptured during

Copyright 1996 by the American Geophysical Union.

Paper number 95JB03036.

0148-0227/96/95JB-03036\$05.00 this sequence are seismic gaps where future large earthquakes may be likely. Thus the Aleutian arc consists of several segments, delineated by boundaries of the aftershock zones of the great earthquakes. Because there is little overlap between aftershock zones of the 1965 and 1957 earthquakes and because the aftershock zones of the 1964 earthquake and the 1938 earthquake abut, this kind of segmentation is used as the basis for estimating seismic potential along the Aleutians [Nishenko and MCCann, 1981]. However, the $1986(M w=8.0)$ shock occurred within the rupture area of the 1957 earthquake, which had been thought to have a low seismic potential for the next few decades [Nishenko and McCann, 1981]. The seismic potential had to be reevaluated [Nishenko and Jacob, 1990] as the apparent segmentation changed based on the aftershock zone of the 1986 earthquake. 


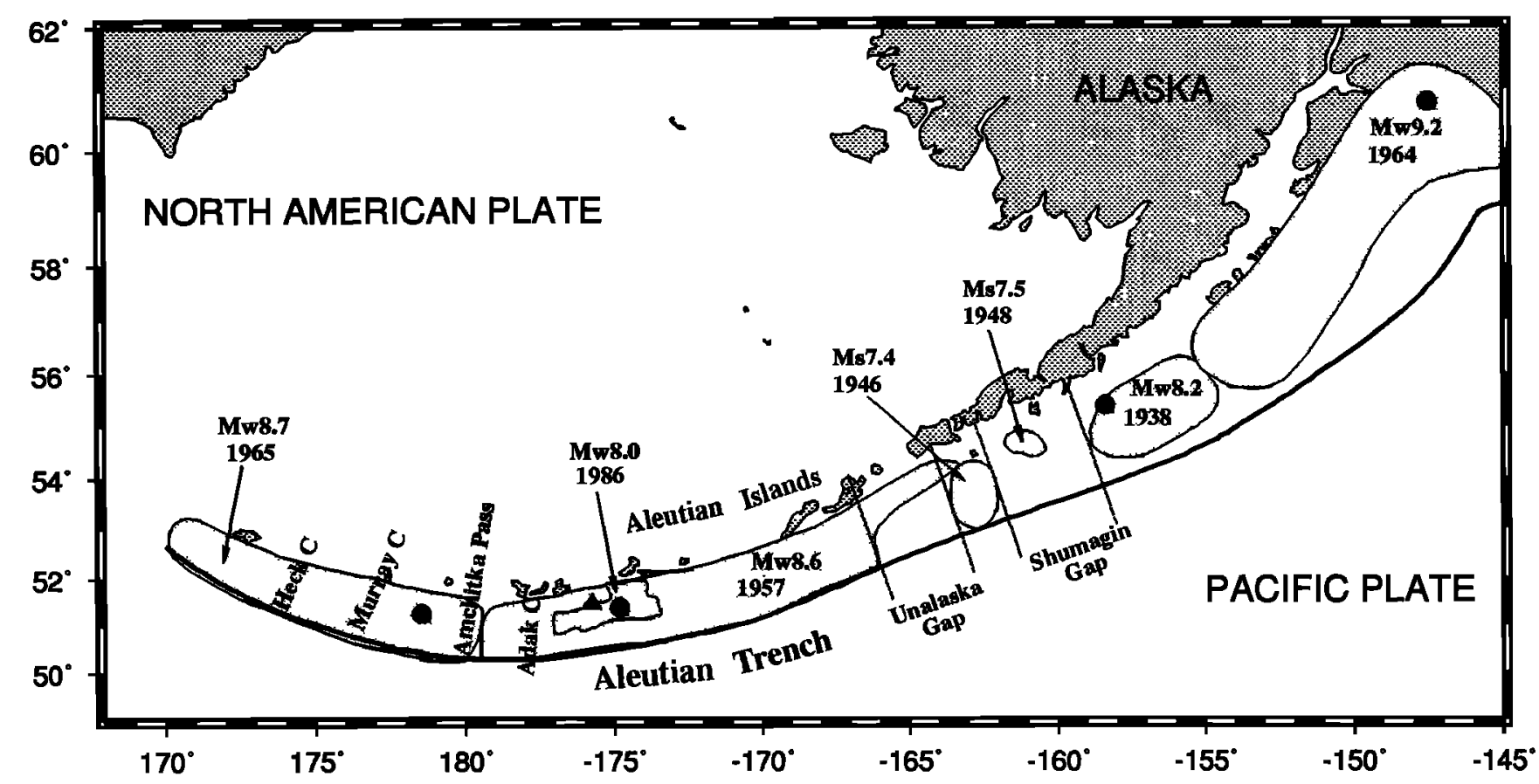

Figure 1. Map of aftershock areas (light shading) of earthquakes with $M s \geq 7.4$ along the Aleutian arc from 1938 to 1986 . The solid circles are the epicenters for the (from left to right) $1965,1986,1938$, and 1964 earthquakes. The solid triangle is the epicenter of the 1957 earthquake. The lines perpendicular to the arc define the Unalaska and the Shumagin ga'ss. Major transverse tear canyons $(\mathrm{C})$ are indicated.

The asperity distributions of great earthquakes may also reflect the heterogeneous stress conditions in the main thrust zone along the Aleutian arc. However, this information is not taken into account when estimating the seismic potential.

The geological evidence for the segmentation of the western Aleutian arc, on the other hand, is based on the facts that the arc is cut by several large transverse canyons (Figure 1). Geist et al. [1988] and Ryan and Scholl [1993] proposed that the western Aleutian arc is composed of discrete clockwise rotating and westward translating blocks, which are bounded by submarine canyons oriented transverse to the arc. In their models, the transverse canyons are formed by differential rotation and along-arc translation of blocks of the arc massif. This segmentation is also used as the basis for estimating the seismic potential and time to failure in the Alaska-Aleutians region [Bufe et al., 1994].

The earthquake focal mechanism data in an area can be used to infer the stress tensor orientation. As earthquakes can occur along faults which are preexisting planes of weakness [McKenzie, 1969], it is not necessarily correct to interpret the $P$ and $T$ axes as the directions of the greatest and least principal stresses. By assuming that the slip on the fault plane occurs in the direction of the resolved shear stress [Bott, 1959; McKen$z i e, 1969$ ] and that the stress orientation is homogeneous in the study area [Angelier, 1979], Gephart and Forsyth [1984] developed an inversion algorithm which finds a best fitting principal stress tensor to a group of earth- quakes by a grid search over a range of possible models. The potential pitfall of this inversion method is that a composite stress tensor may be obtained if the data set is composed of sets from more than one volume with significantly different stress orientations [Michael, 1987] and that this solution may not readily be identified as incorrect. Therefore care must be taken to identify reasonably homogeneous populations of data.

The portion of the average misfit, $F$, that could be due to fault plane solution errors of approximately $10^{\circ}$ was estimated as ranging up to $F=6^{\circ}$, based on synthetic data sets [Wyss et al., 1992; Gillard and Wyss, 1995]. In no data set can we be certain what portion of the average misfit is due to errors of the fault plane solutions and what is due to stress heterogeneity. However, since values of $F \leq 6^{\circ}$ can be explained by modest errors in the fault plane solutions, we will accept results with $F \leq 6^{\circ}$ as satisfying the homogeneity requirement. Inversions with $F>6^{\circ}$ will be suspect of containing some heterogeneous data, although errors in fault plane solutions of approximately $15^{\circ}$ may occur and contribute to an increase of $F$ into the range $6^{\circ}<F<9^{\circ}$. The most informative criterion on homogeneity that we will employ is the following: if subsets of data can be formed by dividing as a function of space or time which results in a substantial reduction of $F$ (say from $F \simeq 6^{\circ}$ to $F$ $\simeq 3^{\circ}$ ), then we conclude that part of the initial misfit was due to heterogeneity.

In this paper, a new method is used to investigate the segmentation of major plate boundaries or faults. We 
hypothesize that stress directions are uniform within segments of the plate boundaries and that they change abruptly across the boundaries between the segments. If this is the case, we should be able to define segments of constant slope in misfit plots. Within each segment we will then be able to calculate meaningful stress directions by inversion of the fault slip data. If we can show that this method works, we will be able to avoid extensive computing, which is necessary if we try to delineate segments of constant stress directions by iterative inversions of many subsets of the data. In this paper we will use the computing-intensive approach of inverting for many data sets using a sliding window, in order to confirm the cumulative misfit method. The statistical significance of our method to identify the segment boundaries is tested quantitatively. We use this method to estimate the segmentation of the Aleutian arc. The relationships between the boundaries of the proposed segmentation along the Aleutian arc, the tectonic features of the oceanic plate, and the asperity boundaries of the great earthquakes are also discussed.

\section{Method}

We assume the stress in a particular large volume is heterogeneous as a whole but can be considered homogeneous in subvolumes. Our purpose is to find where the segmentation boundaries may be located. We propose as a reference tensor the stress model that fits well a subgroup of earthquakes and then calculate the misfit of each individual earthquake with respect to this stress model. The stress model is defined by the azimuths and plunges of the three principal stresses and the measure of stress magnitude, $R$, indicating the magnitude ratio of the intermediate principal stress relative to the two extreme ones $\left(R=\left(\sigma_{2}-\sigma_{1}\right) /\left(\sigma_{3}-\sigma_{1}\right)\right.$, where $\sigma_{1}, \sigma_{2}$, and $\sigma_{3}$ are greatest, intermediate, and least principal stress). The misfit is defined as the smallest rotation angle about an axis of any orientation that would bring the direction and sense of slip, associated with either of the two observed nodal planes, into agreement with the direction and the sense of slip predicted by the stress model.

Earthquakes happen in a three-dimensional space. But the distribution of earthquakes along a major fault or a plate boundary can be simplified into one-dimensional space, that is, by specifying the direction along the strike of the fault and neglecting the depth as a spatial parameter. We order the earthquakes sequentially from one end of the fault to the other. The plot of the cumulative misfit as a function of the earthquake number can then be used to derive some information about the segmentation of the fault [Wyss and $L u, 1995$ ].

In our method, the statistical significance of the stress differences across a boundary of two segments can be quantitatively expressed by the $z$ test (number of samples greater than 30) or the $t$ test (number of samples smaller than 30):

$$
\begin{gathered}
z=\frac{\mu_{1}-\mu_{2}}{\sqrt{\frac{s_{1}^{2}}{n_{1}}+\frac{s_{2}^{2}}{n_{2}}}}, \\
t=\frac{\left(\mu_{1}-\mu_{2}\right) \sqrt{n_{1}+n_{2}}-2}{\sqrt{\left(n_{1}-1\right) s_{1}^{2}+\left(n_{2}-1\right) s_{2}^{2}} \sqrt{\frac{1}{n_{1}}+\frac{1}{n_{2}}}},
\end{gathered}
$$

where $\mu_{1}$ is the mean misfit in segment $1, \mu_{2}$ is the mean misfit in segment $2, s_{1}$ and $s_{2}$ are the standard deviations in the two segments, and $n_{1}$ and $n_{2}$ are the numbers of earthquakes.

\section{Data and Analysis}

The main source for the earthquake focal mechanism data is the Harvard Centroid Moment Tensor (CMT) catalog for the period from 1977 to 1993 . All the earthquakes in this catalog have magnitudes $M w \geq 5.0$. We also collected the available earthquake data with focal mechanisms from the following studies: Stauder and Udias [1963], Stauder and Bollinger [1966], Stauder [1968a, b, 1972], Davies et al. [1981], House and Jacob [1983], and Newberry et al. [1986].

The earthquakes are divided into four distinct groups based on their locations [Taber et al., 1991]: (1) trench and outer rise, (2) main thrust zone, (3) upper plate, and (4) Wadati-Benioff zone. In this paper, only the earthquakes in the main thrust zone are used to study the segmentation of the Aleutian arc.

Most of the seismic strain generated by the plate convergence is released by the earthquakes in the main thrust zone, which generally extends 50 to $120 \mathrm{~km}$ arcward from the trench. The main thrust zone extends to approximately $40-\mathrm{km}$ depth [Tichelaar and Ruff, 1993]. Its thickness is about $10-20 \mathrm{~km}$ [Ekstrom and Eng$d a h l, 1989]$. One important feature is that the region between $173^{\circ} \mathrm{W}$ and $171.5^{\circ} \mathrm{W}$ and the one from $152^{\circ} \mathrm{W}$ to $149^{\circ} \mathrm{W}$ lack moderate-sized earthquakes. There has been no earthquake with $M w \geq 5.0$ in those regions at least since 1977. Another important characteristic is that the main thrust earthquakes seem to cluster. West of $174^{\circ} \mathrm{E}$, the lower part of the main thrust zone lacks seismicity in the $M w \geq 5.0$ range. The upper part of the main thrust zone between $175^{\circ} \mathrm{W}$ and $173^{\circ} \mathrm{W}$ lacks $M w \geq 5.0$ earthquakes.

Our goal is to try to define the segmentation of the Aleutian arc in terms of stress homogeneity. Our data span the period from 1964 to 1993 . However, the great earthquakes may affect the orientation of the stress field. Thus we define the segmentation of the Aleutian arc by the following two steps: we first plot the cumulative misfit as a function of time for the aftershock zones of 1964 and 1986 earthquakes to see whether the stress direction of the aftershock sequence is different from that of the background (before the main shock) and/or from that of the foreground (after the main shock) stress fields. The aftershock sequence is eliminated from the 
data set defining the segmentation if its stress direction differs from that of the background and foreground. The remaining data without the aftershocks are used for the analysis of the stress segmentation of the Aleutian arc. We analyzed the stress distribution with time for the 1964 and 1986 aftershock zones only. The aftershock sequences of the 1957 and 1965 earthquake were not studied because our database does not contain enough information for these two shocks.

We estimated the stress directions using the Focal Mechanism Stress Inversion (FMSI) computer codes of Gephart [1990] for the earthquake focal mechanism data in the western half of the 1957 aftershock zone $\left(173^{\circ} \mathrm{W} / 180^{\circ} \mathrm{W}\right)$ for the period from 1964 to 1993 and employed this as the standard solution, based on which all misfits for individual earthquakes are calculated. The stress model used for the following analyses is $\sigma_{1}=$ $30 / 156, \sigma_{2}=4 / 63, \sigma_{3}=60 / 326$ (plunge and azimuth, respectively), and $R=0.6$.

\section{Stress Changes as a Function of Time}

The cumulative misfit as a function of time for the western part of the 1957 aftershock zone (west of $172^{\circ} \mathrm{W}$ ) is shown in Figure 2a. The main shock of 1986 corresponds to earthquake number 55 . The aftershock sequence of 1986 clearly shows the lowest slope, i.e., the lowest average misfit of $2.2^{\circ}$ compared with an average misfit of $4.0^{\circ}$ for the rest. The last earthquake conforming to the stress pattern of the aftershocks, number 78, took place on October 18, 1986, 6 months after the main shock. Five preshocks, starting from earthquake number 50 (July 17, 1985, 10 months before the main shock), exhibit a stress direction similar to that of the aftershock sequence. We can regard the whole data set in this plot as comprising three sequences with fairly constant misfits (1) earthquake number 1 to 49 , (2) earthquake number 50 to 78 , that is, five preshocks and 24 aftershocks, and (3) earthquake number 81 to 122 , respectively. Using the $z$ test, we find that sequence 1 is similar to sequence 3, but both are significantly different from that of sequence 2 at the $99 \%$ confidence level (Figure 2a). We conclude that the 1986 preshock and aftershock sequence is more homogeneous than earthquakes that occurred at other times in the western Aleutian arc. This difference may be interpreted in two ways. Either the stress tensor was more homogeneous during the preshock and aftershock sequence, or the fault plane solutions of that sequence were more similar to each other than at other times. Thus the data set without the earthquakes number 50 to 78 has fairly constant misfits as a function of time and is used to analyze the stress segmentation of the Aleutian arc.

The cumulative misfit as a function of time for the southwestern part of the 1964 aftershock zone (south of $57^{\circ} \mathrm{N}$ ) is shown in Figure 2b. The events from number 1 (2 months before the main shock) to 3 are the preshocks of the 1964 main shock. A clear change in mean mis-

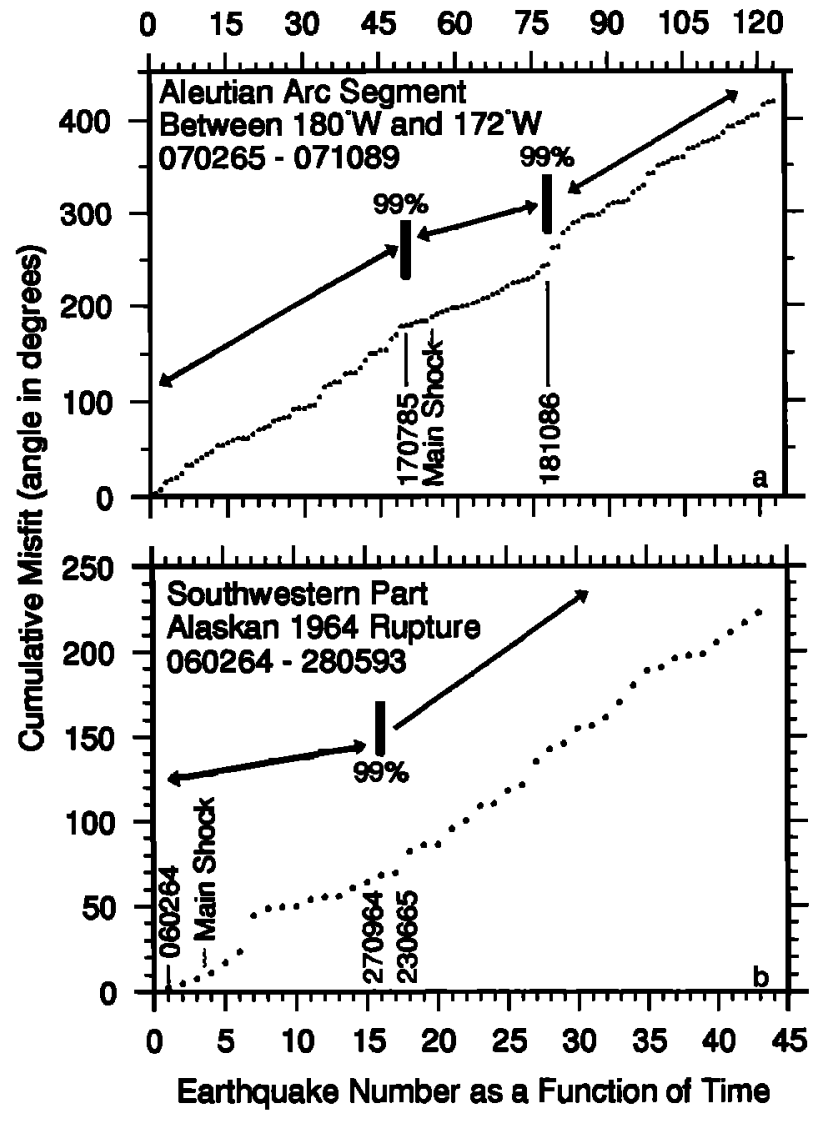

Figure 2. Cumulative misfit angle as a function of earthquake number (a) in the western part of the aftershock zone of the 1957 earthquake and (b) in the southwestern part of the aftershock zone of the 1964 earthquake. The earthquakes are ordered according to time. The occurrence times of several earthquakes are marked. The confidence levels at which neighboring segments are different from each other are indicated.

fit (slope in Figure 2b) occurs at event 18 (June 23, 1965), although one unusually large misfit during the aftershock sequence disturbs the pattern. The average misfits for the period before and after June 23, 1965, are $4.0^{\circ}\left(3.1^{\circ}\right.$ if the single largest misfit of the data set is excluded) and $5.9^{\circ}$, respectively. Since event number 17 , just before the noticeable change in slope, occurred on September 27, 1964, we propose that it is the last undisputable aftershock and thus the foreshock and aftershock sequence in this case is also more homogeneous (or more similar to each other) than the earthquakes occurring at other times. The misfits remain relatively constant between September 27, 1964, and 1993. Again, we conclude that the stress directions derived from the data after September 27, 1964, do not change with time.

From the above analysis of slip vector misfits as a function of time, we conclude that the aftershock sequences of the 1964 and 1986 events can be interpreted as reflecting a more homogeneous stress tensor than those of the foreground and background sequences. The homogeneity conditions last approximately 1 year. Dur- 


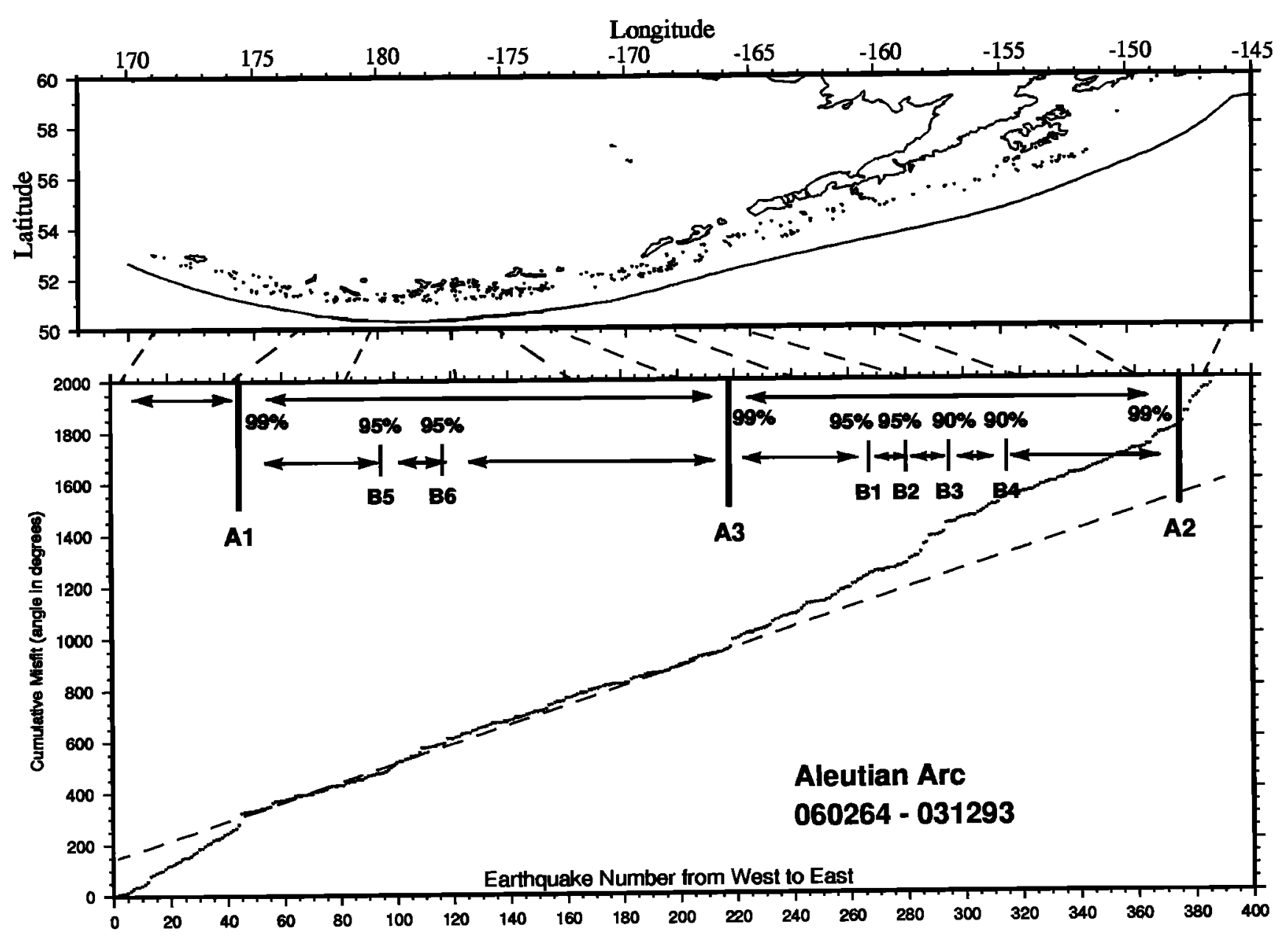

Figure 3. (top) The epicenters of the earthquakes are shown as dots in the upper plot. (bottome) Cumulative misfit as a function of earthquake numbers which are ordered from west to east for the time interval from 1964 to 1993 is shown. The significance levels at which the neighboring segments are different from each other are indicated in the bottom figure. Notice the abscissa of the bottom figure is in units of earthquake number while that of the top figure is in longitude. The longitude locations of event numbers $40,80, \ldots, 400$ are pointed out by dashed lines.

ing the rest of time, the stress directions remain approximately constant.

\section{Stress Changes as a Function of Space}

All 386 earthquakes which occurred in the main thrust zone, not counting the aftershock sequences of both 1964 and 1986 mainshocks, are used for analyzing the segmentation of the Aleutian arc for the time interval from 1964 to 1993 . The earthquakes are ordered from the west (from about $170^{\circ} \mathrm{E}$ ) to the east till about $145^{\circ} \mathrm{W}$. Their epicenters and the cumulative misfit are shown in the upper and lower plots of Figure 3, respectively. It is noted that the abscissa of the lower plot is in units of event numbers, which produce a variable distance scale. In order to identify the geographic locations of data segments in the lower plot, dashed lines connect - some points of the two distance scales. In the cumulative misfit curve we notice that differences in slope (mean misfit) exist but that within segments the slope is fairly constant. This is consistent with our hypothe- sis that the stress tensor orientation is constant within segments of the plate boundary and that differences between segments can be measured quantitatively. The statistical significance levels of the differences in mean misfit between neighboring segments are also shown in Figure 3.

The most significant change of the slope of the cumulative misfit (Figure 3) takes place near earthquake number 45 , which corresponds to a longitude of about $177.5^{\circ} \mathrm{E}$. The second most significant change of the slope occurs near $149^{\circ} \mathrm{W}$ longitude and corresponds to the earthquake number 375 , approximately. The mean misfits of the segment west of $177.5^{\circ} \mathrm{E}$ and the one east of $149^{\circ} \mathrm{W}$ are different at the $99 \%$ level from any segment of the sequence, and these segments are apparently separated from the rest by the two most pronounced boundaries. We will call them boundaries A1 and A2. Between A1 and A2, there exists an additional highly significant ( $99 \%$ confidence) boundary, A3, which is located near $173^{\circ} \mathrm{W}$ (event 218). 


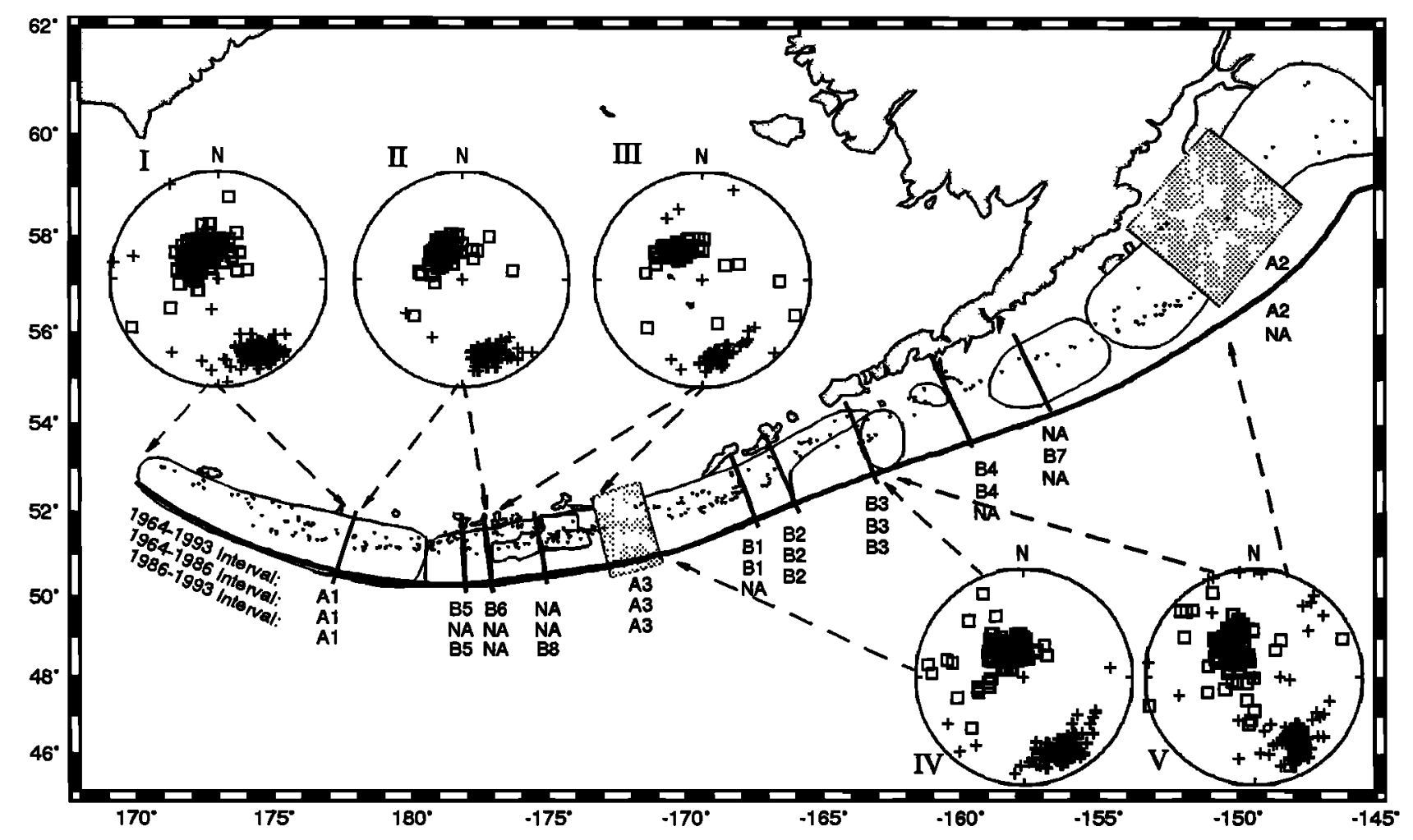

Figure 4. Epicenters of the earthquakes (dots) from 1964 to 1993 and segmentation boundaries of the Aleutian arc based on the stress distribution for the time intervals from 1964 to 1993, 1964 to 1986 , and 1986 to 1993 , respectively. The lines perpendicular to the arc indicate the boundaries of the segmentation along the Aleutian arc based on the analyses for the three time intervals and one reference stress tensor. NA means the stress boundary is not applicable for that period. The orientations of $P$ (plusses) and $T$ (squares) axes of the focal mechanism data in the five segments are plotted on lower hemisphere, equal-area projections.

The region between $\mathrm{A} 3$ and $\mathrm{A} 2$ can be divided by four additional boundaries, named B1, B2, B3, and B4, with significance levels ranging from $90 \%$ to $95 \%$. B2 corresponds to the eastern end of the 1957 aftershock zone, B1 is about $100 \mathrm{~km}$ west of B2, B3 is the eastern end of the Unalaska gap, and B4 is located in the middle of the Shumagin gap.

The slope in the cumulative misfit plot for the area between $\mathrm{A} 1$ and $\mathrm{A} 3$ is quite constant, except for a transition zone defined by the boundaries $\mathrm{B} 5$ and $\mathrm{B} 6$. These two boundaries correspond to the western edge of the 1986 earthquake.

We also tested whether or not the stress segmentation changes with time. The number of data points does not allow division into more than two sets: we examined separately the data before and after the 1986 main shock. The analysis for the period between 1964 and 1986 indicated that B7 is an additional segment boundary (Figure 4). The results for the interval from 1986 to 1993 show B8 is a boundary (Figure 4).

Based on the above analyses, we conclude that essentially the same segmentation is derived from the entire data set and from the sets of two time intervals. Thus temporal changes, other than those due to major aftershock sequences discovered above, do not exist in the stress regime, and we may use the entire data set as the most representative sample.

\section{Stress Segmentation Sensitivity to the Reference Stress Model}

We analyzed the cumulative misfit plots by choosing several different reference stress models. As our method is based on the changes of stress direction and as the relationship between misfits and stress models is nonlinear, it is possible that some of the segment boundaries do not show up relative to a particular reference stress tensor. We used the following four reference stress models to investigate the changes of slopes of cumulative misfit curves, model 1: $\sigma_{1}=6 / 352, \sigma_{2}=0 / 82, \sigma_{3}=$ $84 / 175$ (plunge and azimuth, respectively), and $R=0.2$; model 2: $\sigma_{1}=30 / 156, \sigma_{2}=4 / 63, \sigma_{3}=60 / 326$, and $R$ $=0.6$, which is the same reference stress model used to estimate the segmentation boundaries $\mathrm{A} 1$ to $\mathrm{A} 3$ and $\mathrm{B} 1$ to B8 (Figure 4); model 3: $\sigma_{1}=57 / 155, \sigma_{2}=17 / 233$, $\sigma_{3}=27 / 12$, and $R=0.9$; model $4: \sigma_{1}=2 / 49, \sigma_{2}=$ $4 / 139, \sigma_{3}=86 / 291$, and $R=0.4$. These stress tensors are derived by inverting four patches of homogeneous earthquake focal mechanism data along the Aleutians. Figure 5 is the cumulative misfit angle as a function of 


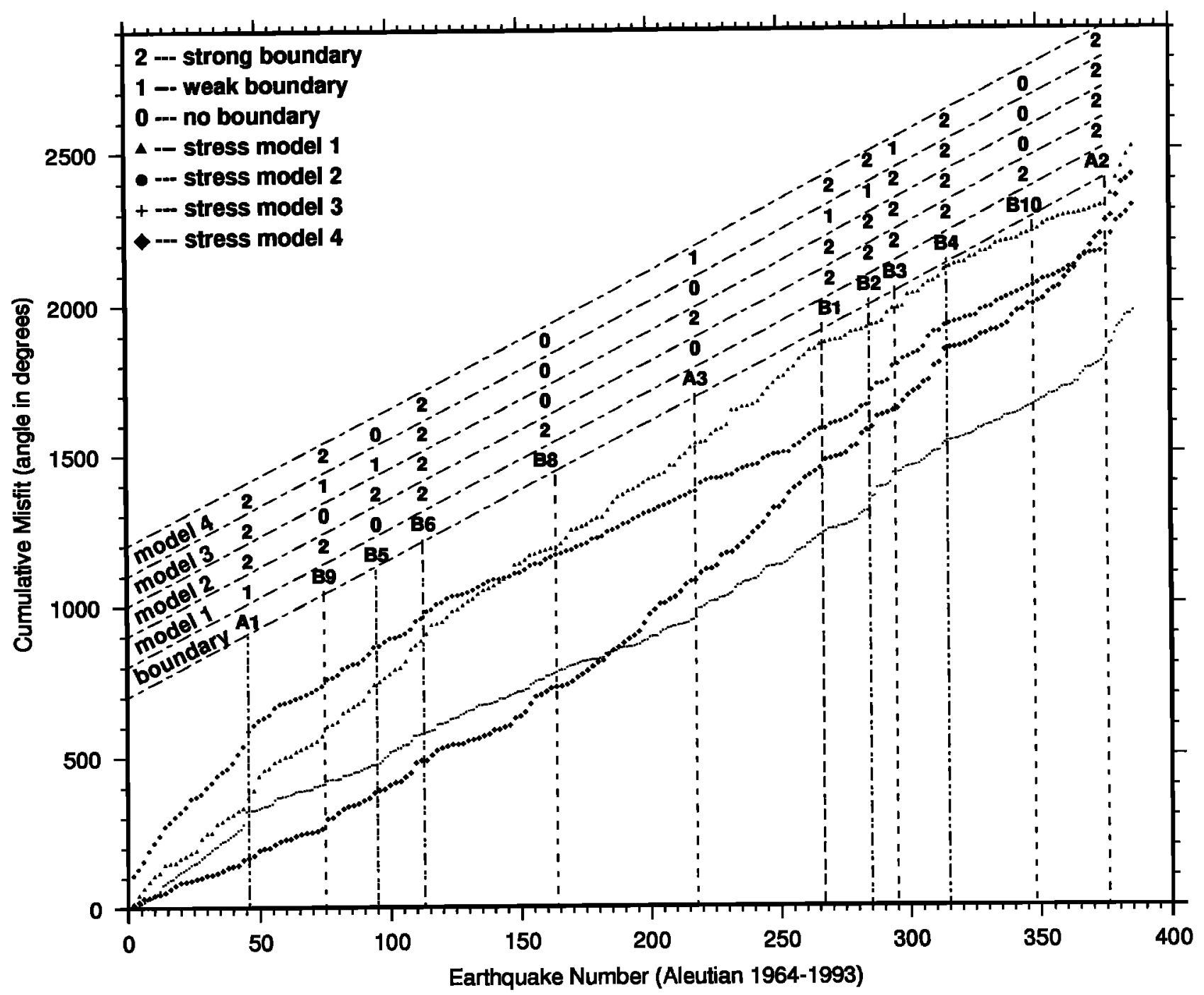

Figure 5. Cumulative misfit as a function of earthquake numbers for four reference stress tensors. For clarity, only the even number of earthquakes is shown in the curves with reference stress models 1,3 , and 4 , while all the earthquakes are shown in that with the reference stress model 2. The significance of the segmentation, from no boundary, to weak boundary, and to strong boundary, is indicated by 0,1 , and 2 , respectively.

earthquake number for the four reference stress tensors. We use 0,1 , and 2 to rank the significance of the segmentation from no boundary, to weak boundary, and to strong boundary (Figure 5).

A new boundary, B9 (Figure 5), not found by using stress model 2, was picked up by reference stress models 1,3 , and 4 . Using model 1 as the reference stress tensor, we found a boundary B10 (Figure 5). B9 is located at Amchitka Pass, the segment boundaries between the aftershock zones of 1957 and 1965 earthquakes (Figure 1). B10 is the location where the aftershock zones of 1964 and 1938 abut (Figure 1).

It seems that our method is not robust enough to define all the stress segmentation boundaries by employing only one reference stress tensor. By comparing cumulative misfit curves, we also found that the location of segment boundaries shifts by approximately five earthquakes, which may correspond to several to tens of kilometers in distance.

\section{Confirmation of Segment Boundaries by Stress Inversion in Moving Windows}

We performed stress inversions in a moving window along the strike of the Aleutian arc to check on the reliability of the segmentation boundaries derived based on the cumulative misfit curves. This method is based on the assumption that average misfit angles will become bigger if the segmentation boundaries fall within the window. Therefore the segmentation boundaries should be near the peaks of curves of average misfit versus window position. The procedure of stress inversion in a moving window is as follows. The focal mechanism data are inverted using FMSI codes for earthquakes within the window. The average misfit angle is determined, 


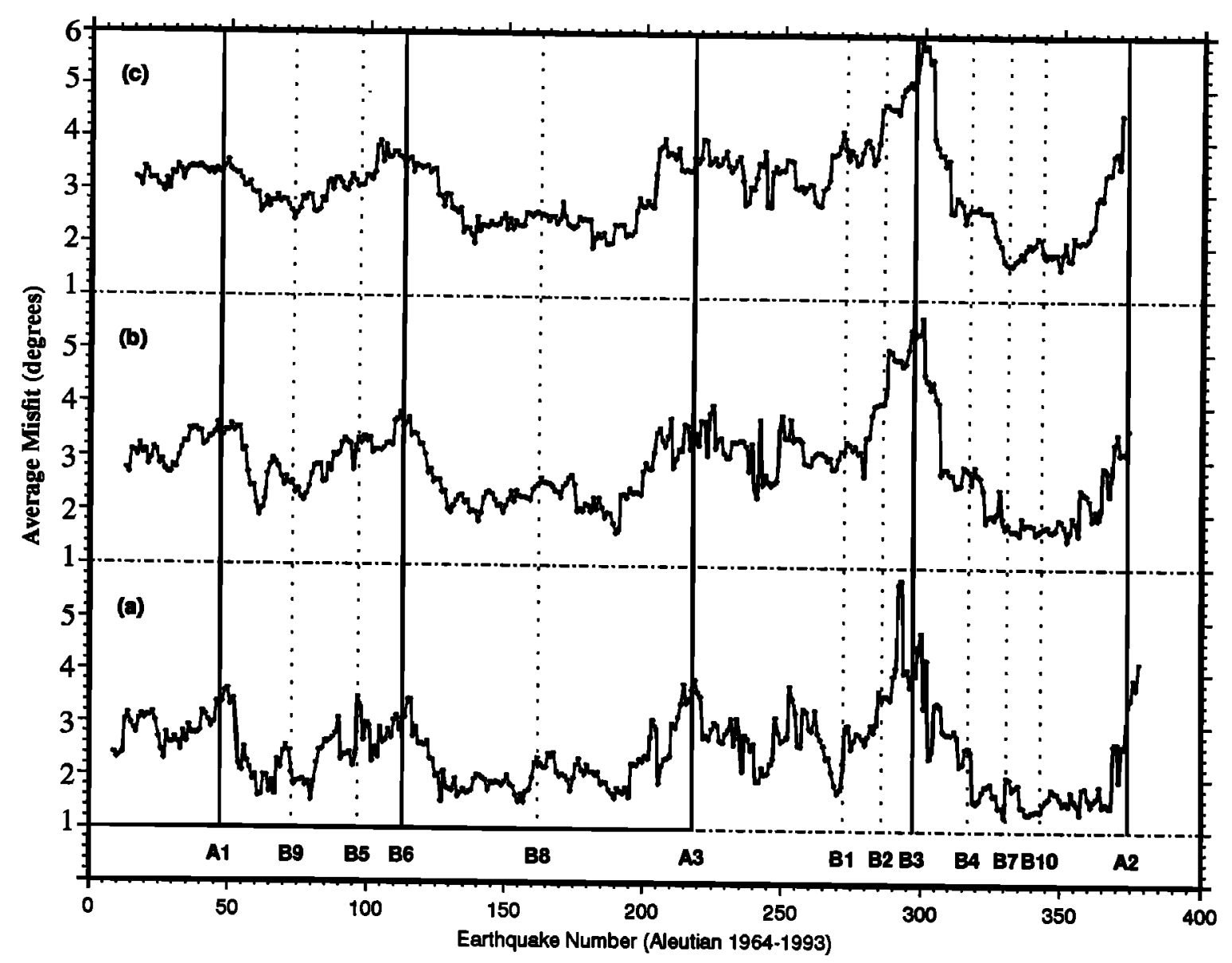

Figure 6. Average misfit angle for inversions for stress directions as a function of positions of the moving window for three different window lengths, (a) 17, (b) 25 , and (c) 31 earthquakes. The locations of segmentation boundaries based on the analysis of cumulative misfit, A1 to A3 and $\mathrm{B} 1$ to $\mathrm{B10}$, are shown by vertical lines. Large misfits result when events from segments with different stress directions are mixed in a window.

and the window is advanced by one earthquake along the strike of the arc.

Figure 6 shows the average misfit angle as a function of position of the moving window for three different window lengths, 17, 25, and 31 (Figures $6 \mathrm{a}, 6 \mathrm{~b}$, and $6 \mathrm{c}$, respectively). The three curves in Figure 6 have similar features and trends. There are five major peaks, which correspond to segment boundaries A1, B6, A3, B3, and A2.

The inversion of subsets in many parts of the Aleutians leads to very low average misfits $1.8^{\circ} \leq F^{\prime} \leq 3^{\circ}$. We made the reasonable assumption that the quality of focal mechanisms is constant throughout our data set and interpret inversions resulting in $F>3^{\circ}$ as being partially contaminated by stress heterogeneity. The clearest peaks of average misfit in Figure 6 are those confirming boundaries B3 and A2. The increased value of $F$ is also very clear at boundaries $\mathrm{B} 6$ and $\mathrm{A} 3$ when compared with the segment between these two boundaries. The boundary $\mathrm{A1}$, which is clearly defined by the cumulative misfit curves, shows the most poorly developed peak in Figure 6. The high level of $F$ in the seg- ment between A3 and B3 suggests a relatively high level of heterogeneity exists in that segment.

Based on the analyses of cumulative misfit curves and stress inversion in a moving window, we propose that there exist five first-order boundaries, A1, B6, A3, B3, and A2, along the strike of Aleutian arc (Figure 6). A further subdivision is composed of several second-order boundaries, B9, B5, B8, B1, B2, B4, B7, and B10, from west to east in the study region. The terms of firstorder and second-order refer to our ability to resolve the presence of the boundary; however, they may not necessarily describe the degree of tectonic significance.

\section{Principal Stress Orientation}

The Aleutian arc can be divided into five major segments based on the locations of first-order boundaries (Figure 6 and 7 ) : the first is from $170^{\circ} \mathrm{E}$ to boundary $A 1$, the second is from boundary $A 1$ to $B 6$, the third is from $\mathrm{B} 6$ to $\mathrm{A3}$, the fourth is from $\mathrm{A3}$ to $\mathrm{B3}$, and the last is from B3 to A2. Segments 2, 3, 4, and especially segment 5 can be further divided into several subsegments. 


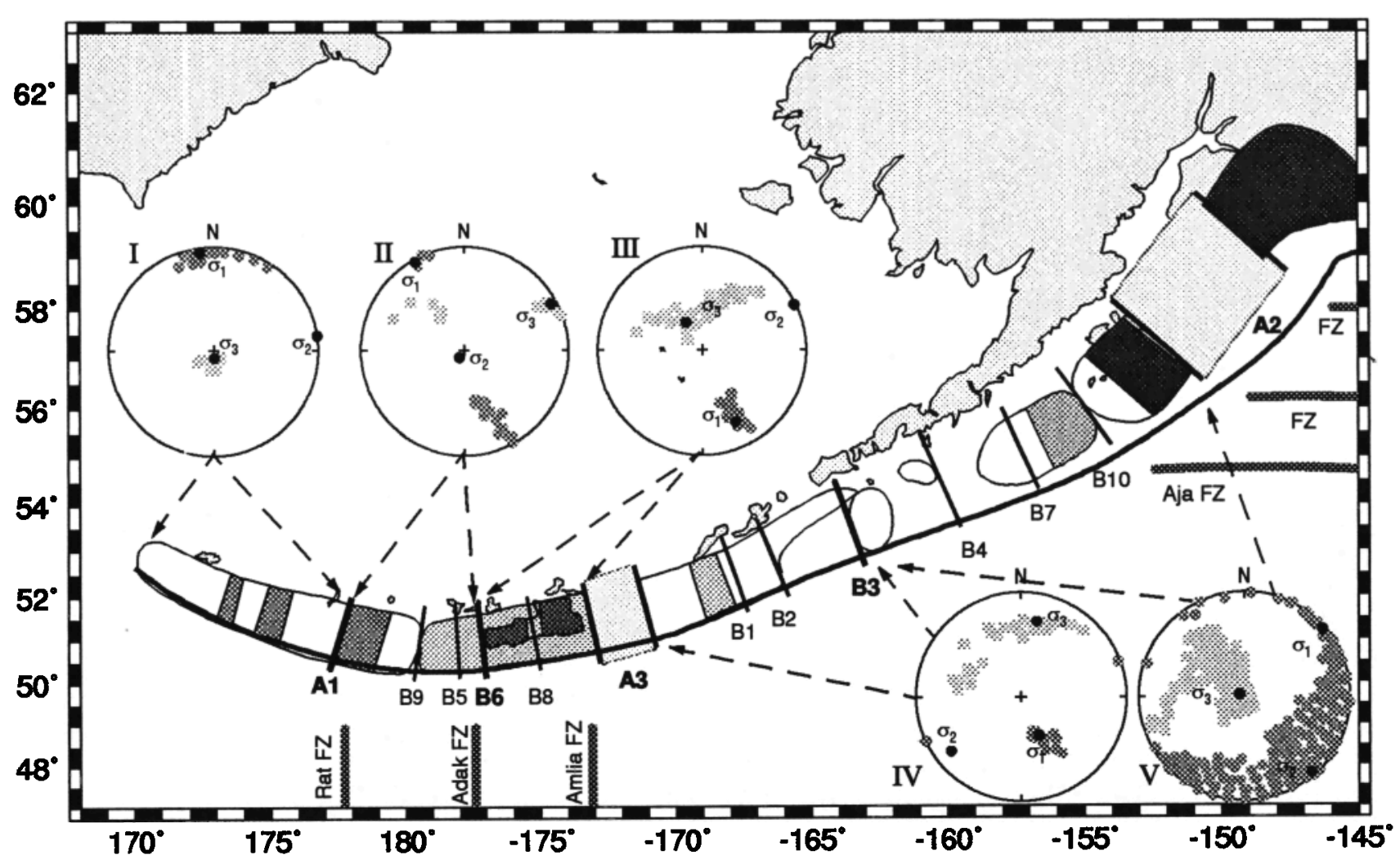

Figure 7. Segmentation of the Aleutian arc based on the stress distribution estimated from fault plane solutions. The lines perpendicular to the plate boundary are the segmentation boundaries. The principal stress orientations for the five major segments are plotted on lower hemisphere, equal-area projections in which the $95 \%$ confidence regions are defined by circles and squares for the greatest and least principal stress, respectively. The major fracture zones (FZ) are indicated. The shaded areas are the asperities of great earthquakes. The asperities of 1957 and 1938 earthquakes are modified from Johnson et al. [1994] and Johnson and Satake [1994], respectively. The aftershock areas of the great earthquakes are the same as those shown in Figure 1.

The inversion algorithm by Gephart [1990] is used to find a best fitting principal stress tensor expressed by the plunges and azimuths of the three principal stresses and the relative magnitude of the principal stresses, $R$. The $95 \%$ confidence areas are derived based on the one-norm misfit statistics [Gephart and Forsyth, 1984; Gephart, 1990].

The orientations of the principal stresses for the five major segments are shown in Figure 7 and listed in $\mathrm{Ta}$ ble 1. The $P$ and $T$ axes of the focal mechanisms used to invert the stress orientations are shown in Figure 4. In segment 1 , the greatest principal stress strikes almost north-south horizontally, and the least principal stress plunges vertically. The $95 \%$ confidence region of the greatest principal stress is completely resolved from that of the least principal stress. In segment 2, the greatest principal stress has similar orientation to that in segment 1. The direction of least principal stress changes from vertical in segment 1 to horizontal in segment 2. The $95 \%$ confidence region of the least principal stress is resolvable from that of the greatest principal stress but not from the intermediate principal stress. The greatest principal stress in segment 3 shows an az- imuth similar to that in segment 2 but with a steeper plunge of $25^{\circ}$. The orientation of the least principal stress cannot be resolved from that of the intermediate stress at the $95 \%$ level. The greatest principal stress in segment 4 shows the same azimuth as that in segment 3 but a much steeper plunge of $57^{\circ}$. The least principal stress is resolved from the intermediate principal stress at the $95 \%$ confidence level. The greatest principal stresses in segment 5 are not well constrained. The least principal stress is oriented vertically, but the $95 \%$ confidence regions of the greatest and the intermediate stress overlap.

\section{Discussion}

The method of plotting the cumulative misfit as a function of space along arc has been used to investigate the segmentation of the Aleutian main thrust zone. The dependence of the results on the stress model used to calculate misfit was investigated. The overall best fitting stress tensor is not suitable for our method because it evenly distributes errors among all segments. We find that seven of the boundaries are identified using the 
Table 1. Stress Tensor Inversion

\begin{tabular}{|c|c|c|c|c|c|c|c|c|c|}
\hline \multirow{2}{*}{ Segment } & \multirow{2}{*}{$\begin{array}{l}\text { Sample } \\
\text { Number }\end{array}$} & \multicolumn{2}{|c|}{ Greatest Stress } & \multicolumn{2}{|c|}{ Intermediate Stress } & \multicolumn{2}{|c|}{ Least Stress } & \multirow{2}{*}{$\boldsymbol{R}$} & \multirow{2}{*}{$\begin{array}{l}\text { Average } \\
\text { Misfit }\end{array}$} \\
\hline & & AZ & PL & $\mathbf{A Z}$ & PL & $\mathbf{A Z}$ & PL & & \\
\hline I & 44 & $352^{\circ}$ & $6^{\circ}$ & $82^{\circ}$ & $0^{\circ}$ & $175^{\circ}$ & $84^{\circ}$ & 0.2 & $2.8^{\circ}$ \\
\hline II & 55 & $331^{\circ}$ & $3^{\circ}$ & $212^{\circ}$ & $83^{\circ}$ & $62^{\circ}$ & $6^{\circ}$ & 0.4 & $2.9^{\circ}$ \\
\hline III & 109 & $155^{\circ}$ & $25^{\circ}$ & $64^{\circ}$ & $2^{\circ}$ & $330^{\circ}$ & $65^{\circ}$ & 0.6 & $3.4^{\circ}$ \\
\hline IV & 73 & $155^{\circ}$ & $57^{\circ}$ & $273^{\circ}$ & $17^{\circ}$ & $12^{\circ}$ & $27^{\circ}$ & 0.7 & $3.4^{\circ}$ \\
\hline $\mathbf{v}$ & 100 & $69^{\circ}$ & $3^{\circ}$ & $160^{\circ}$ & $22^{\circ}$ & $332^{\circ}$ & $68^{\circ}$ & 0.4 & $5.5^{\circ}$ \\
\hline
\end{tabular}

$A Z$ is azimuth; PL is plunge; $R$ is ratio of relative stress magnitude (see text).

stress tensors best fitting four homogeneous segments. Five additional boundaries are only defined using some of the stress models. We conclude that we cannot be certain that we have found all existing boundaries in stress directions, but the locations of change found by our method represent real boundaries. At these boundaries the stress directions either change or at least the tectonic style goes from one of homogeneous to relatively heterogeneous stress directions. We confirm the conclusion by Wyss and $L u$ [1995] that some segmentation of plate boundaries can be mapped by the cumulative misfit method.

The significance levels based on the $z$ test or $t$ test can be used to measure the degree to which the two neighboring segments are different. The results of the inversion of focal mechanism data by a moving window analysis further demonstrate the success of our method. The principal stress orientations from the inversions of focal mechanism data (Figure 7) agree with the results from maximum horizontal stress trajectories by some researchers [e.g., Nakamura et al., 1977; Nakamura and Uyeda, 1980; Estabrook and Jacob, 1991] and are generally consistent with the direction of convergence between the Pacific and North American plates.

The idea that the large-scale structural features on the oceanic plates may have profound effects on the subduction process was proposed by several researchers [e.g., Vogt et al., 1976; Kelleher and McCann, 1976; House and Jacob, 1983]. One of the significant factors that affects the subduction process of the Aleutian arc may be the fracture zones in the Pacific plate. There are several fracture zones in the study area. They are the Rat, the Adak, the Amlia, the Aja, and two unnamed fracture zones north of the Aja fracture zone (Figure 7). The delineation of the fracture zones is mainly based on the magnetic anomalies and sometimes on the bathymetric topography in the Pacific plate.

The Rat fracture zone offsets the magnetic anomalies about $80 \mathrm{~km}$ left laterally at a trough along $177.7^{\circ} \mathrm{E}[\mathrm{Er}$ ickson et al., 1970; Rea and Dixon, 1983]. The northward projection of the Rat fracture zone intersects the
Aleutian arc at the location of boundary A1 in the segmentation analysis (Figure 7).

The Adak fracture zone trends north-south with an axis at about $177.4^{\circ} \mathrm{W}$, as indicated by the bathymetric and magnetic anomaly data [Grim and Erickson, 1969; Rea and Dixon, 1983]. Magnetic anomaly profiles across the Adak fracture zone show an apparent left lateral offset of about $30 \mathrm{~km}$. The northern projection of the Adak fracture zone, which lies just east of Adak canyon, separates regions of strikingly different topography. For example, the seafloor east of the canyon is relatively smooth, whereas the seafloor to the west is chaotic and deeply incised by canyons [Perry and Nichols, 1965]. The Adak fracture zone intersects the Aleutian arc in the transition zone defined by boundary B6 in our segmentation.

The Amlia fracture zone intersects the Aleutian trench near $173.2^{\circ} \mathrm{W}$ (Figure 7). It offsets the magnetic anomalies of the Pacific plate about $220 \mathrm{~km}$ in a left lateral sense [Hayes and Heirtzler, 1968; Grim and Erickson, 1969]. Both the volcanic line (on the overriding plate) and the subducting plate (oceanic plate) are offset horizontally by about $40 \mathrm{~km}$ in a right-lateral sense near the downdip projection of the Amlia fracture zone [House and Jacob, 1983]. Seismicity studies by Engdahl et al. [1982] support the existence of this feature, since east of about $176^{\circ} \mathrm{W}$ the intermediate-depth seismic zone becomes progressively more offset to the south of the volcanic line as longitude $173^{\circ} \mathrm{W}$ is approaclied. House and Jacob [1983] suggest that as the offset of the downgoing plate moves slowly westward, it may cause a mass deficiency between the subducting slab and the overriding plate. This may cause both an upwelling of the asthenosphere above the slab and the subsidence in the overriding lithosphere, explaining the occurrence of the summit basins and a 40-km offset in the volcanic arc. Another result of the mass deficiency and subsidence may be $a$ temporary decrease in coupling between the subducting and overriding plates along the main thrust zone such that the seismicity in the main thrust zone may temporarily (of the order of a few million years) decrease 
or disappear. Figure 4 shows that the main thrust zone between $171.5^{\circ} \mathrm{W}$ and $173^{\circ} \mathrm{W}$ currently lacks moderatesized earthquakes and suggests that this area may experience aseismic slip because of the reduced coupling. The northward projection of the Amlia fracture zone lies at the western margin of the wide boundary A3 formed in our segmentation analysis.

The Aja fracture zone is oriented east-west and offsets the magnetic anomalies about $150 \mathrm{~km}$ left laterally [Naugler and Wageman, 1973; Owen, 1983] (Figure 7). The westward projection of the Aja fracture zone may intersect the subduction zone in the middle of the 1938 aftershock zone and corresponds to the boundary B7 in our segmentation. However, the location of the Aja fracture zone by Naugler and Wageman [1973] is different than that by Owen [1983]; thus we are not confident on the relationship between boundary B7 and Aja fracture zone. There exist two unnamed fracture zones intersecting the plate boundary in the 1964 rupture area [Naugler and Wageman, 1973; Owen, 1983] (Figure 7). Both of these strike east-west and are left lateral. The arc segment between the intersection of these two fracture zones is an area lacking moderatesized earthquakes and it coincides with our wide boundary $\mathrm{A} 2$.

The amplitudes of the magnetic anomalies are sharply reduced where the fracture zones intersect the trench, resulting in a 100-km-wide magnetically "quiet zone" over most of the Aleutian trench and terrace [Hayes and Heirtzler, 1968; Grim and Erickson, 1969]. Because of the quiet zone, we cannot be certain that these fracture zones continue all the way into the trench, and our correlation may not be correct. However, Lonsdale [1988] suggested that the Amlia fracture zone actually extends north to underlie the Aleutian arc, and Mogi [1969] recognized an influence of the fracture zone in the pattern of the 1957 earthquake's aftershock sequence, although Sykes [1971] emphasized that the Amlia fracture zone did not act as a boundary for the rupture zone of this event.

We conclude that some major boundaries in the stress orientation may be controlled by fracture zones in the subducting plate. This may result from topographic irregularities and the age difference of the seafloor across the fracture zones.

The boundaries defined by our method may also be related to the asperity distributions of the great earthquakes. The asperities considered here refer to the area of highest seismic moment release, assumed to be the strongest coupling between the subducted and the overriding plate [e.g., Ruff and Kanamori, 1983; Beck and Christensen, 1991; Dmowska and Lovison, 1992; Christensen and Beck, 1994; Johnson et al., 1994].

The seismic moment release of the 1938 earthquake is concentrated in the eastern half of the aftershock zone (Figure 7) [Johnson and Satake, 1994], that is, east of B7 of our segmentation. The eastern boundary of the 1938 aftershock zone corresponds to B10 of our segmen- tation boundary. B10 is poorly defined in our analysis, which may be attributed to the limited earthquake focal mechanism data in the 1938 aftershock zone area. The existence of B10 supports the conclusion that there is a tectonic boundary between the 1964 and 1938 earthquake where the aftershock zones of the two earthquakes abut [e.g., Sykes, 1971; Christensen and Beck, 1994].

The asperity areas of the 1957 main shock (modified from Johnson et al. [1994]), are shown in Figure 7. The aftershock zone of 1957 is separated into two segments by the Amlia fracture zone, which is also the boundary A3 of our result. Most of the moment release was concentrated in the western half of the aftershock zone based on the surface and tsunami wave inversion [Johnson et al., 1994], which is therefore the biggest asperity area of this earthquake. There is also another small asperity between $169^{\circ} \mathrm{W}$ and $168^{\circ} \mathrm{W}$. The western end of the larger asperity is $\mathrm{B} 9$ of our analysis. The existence of $\mathrm{B} 9$ may also support the idea that the Amchitka Pass played an important role in ending the ruptures of 1965 and 1957 earthquakes [e.g., Stauder, 1972; Ryan and Scholl, 1993]. The eastern end of the second asperity is approximately defined by boundary B1, which is also the location suggested by Johnson et al. [1994] as the end of the 1957 rupture. Boundary 132 in the stress direction corresponds to the eastern end of the aftershock zone.

The 1964 earthquake had two major asperities, separated by a gap of about $200 \mathrm{~km}$ [Christensen and Beck, 1994]. The boundary A2 in our analysis clearly separates the two asperity areas (Figure 5).

There are three major asperities in the 1965 rupture process (Figure 7). The largest and first asperity extends from the epicenter to $100 \mathrm{~km}$ to the WNW [Beck and Christensen, 1991]. The boundary A1 corresponds to the west end of the largest asperity. The second pulse of moment release is jagged and is less coherent between stations. The last resolvable asperity extends from 360 to $420 \mathrm{~km}$ WNW of the epicenter. Both the second and the last asperity boundaries cannot be resolved by our analysis.

The aftershock zone of the 1986 earthquake extends to boundary A3 to the east and boundary B6 to the west (Figure 7). Most of the moment release of the 1986 earthquake was generated in the neighboring regions of the epicenter, and very little moment was released near the epicenter of the main shock [Yoshida, 1992; Das and Kostrov, 1990; Hwang and Kanamori, 1986; Boyd and Nabelek, 1988]. The boundary B8 separates the two major asperity areas of the 1986 rupture (Figure 7).

Boundary B4 lies in the middle of the Shumagin seismic gap, which may suggest that the west and east of the Shumagin gap may behave differently [e.g., $L u$ et al., 1994]. This supports the hypothesis that the Shumagin gap can be divided into western and eastern parts based on the transition from double to single Wadati-Benioff seismic zone [Hudnut and Taber, 1987].

The transverse canyons in the western Aleutians (Fig- 
ure 1) trend nearly at right angles to the regional slip vector of the plate motion. Gates and Gibson [1965] provided some geologic evidence to show that all the transverse canyons are not of erosional origins. The Adak canyon is one of the most prominent canyons and is the only one which correlates with a stress boundary. LaForge and Engdahl [1979] studied small magnitude earthquakes in the wedge-shaped zone above the main thrust zone in the Adak canyon region. Evidence from the focal mechanisms for normal faulting in the wedge led them to conclude that Adak canyon is a block-fault structure caused by lateral extension of the overriding plate. However, Spence [1977] suggested that the Adak canyon is the result of the existence of the topographic relief of the Adak fracture zone. We suggest that the transverse canyons might be tectonic in origin but may be related to the curvature of the western Aleutian trench with respect to the slip direction of the subducted plate as the canyons are generally absent in the Aleutian arc east of $177^{\circ} \mathrm{W}$. The canyons may also be related to the earthquakes in the upper plate and do not significantly affect processes in the main thrust zone. This may be the reason why these canyons appear not to influence the stress directions.

\section{Conclusions}

The method of plotting the cumulative misfit as a function of earthquake numbers, which are ordered in space, is proposed for investigating the stress homogeneity of the Aleutian arc. Using this method, one can divide the area into subareas where the stresses are homogeneous. We conclude that the aftershock sequences of the 1964 and 1986 events appear more homogeneous than those of the foreground and background sequences, based on the analysis of slip vector misfits as a function of time. The homogeneity condition of the aftershock sequence (sometimes also containing several preshocks) lasts approximately 1 year.

The cumulative misfit as a function of earthquake number along the strike of the arc shows that the Aleutian arc (from $170^{\circ} \mathrm{E}$ to $145^{\circ} \mathrm{W}$ ) can be divided into five major segments. The focal mechanism data in the stress-homogeneous segments are then used to invert the principal stress orientations using FMSI computer codes of Gephart [1990]. The stress inversion analysis in a moving window and the orientations of the principal stresses in the five segments support the feasibility of our method.

We considered the correlation of the stress boundaries with four other tectonic features: fracture zones, submarine canyons, ends of the aftershock zones of great ruptures, and asperities. The strongest correlation seems to exist between fracture zones and stress direction changes. This may be interpreted as indicating a decoupling within the underthrusting plate along the zones of weakness (the fracture zones) across which stress may not be transmitted fully. The correlation of morphological features, such as canyons, with stress discontinuities is weakest. This suggests that most of the canyons may not influence the process in the lower crust. Further, a fairly strong correlation of asperities and ends of ruptures with location of stress discontinuity is observed.

Acknowledgments. This work was supported by NSF grant 9118086 and in part by the Wadati foundation at the Geophysical Institute of the University of Alaska Fairbanks. We greatly appreciate J. Gephart for comments to improve the method and suggestions to confirm the method by moving window analysis. We thank D. Christensen, J. Lahr, D. Gillard, J. Beniot, S. McNutt, N. Biswas, R. Zuniga, S. Wiemer, and H. Fletcher for discussions and comments. We also thank C. Bufe and an anonymous reviewer for useful comments.

\section{References}

Angelier, J., Determination of the mean principal directions of stresses for a given fault population, Tectonophysics, 56, T17-T26, 1979.

Beck, S. L., and D. H. Christensen, Rupture process of the February 4, 1965, Rat Islands earthquake, J. Geophys. Res., 96, 2205-2221, 1991.

Bott, M. H. P., The mechanics of oblique slip faulting, Geol Mag., 96, 109-117, 1959.

Boyd, T. M., and J. L. Nabelek, Rupture process of the Andreanof Islands earthquake of May 7, 1986, Bull. Seismol. Soc. Am., 78, 1653-1673, 1988.

Bufe, C. G., S. P. Nishenko, and D. J. Varnes, Seismolicity trends and potential for large earthquakes in the AlaskaAleutian region, Pure Appl. Geophys., 142, 83-99, 1994.

Christensen, D. H., and S. L. Beck, The rupture process and tectonic implications of the great 1964 Prince William Sound earthquake, Pure Appl. Geophys., 142, 29-53, 1994.

Das, S., and B. V. Kostrov, Inversion for seismic slip rate history and distribution with stabilizing constraints: Application to the 1986 Andreanof Islands earthquake, $J$. Geophys. Res., 95, 9-6913, 1990.

Davies, J., L. Sykes, L. House, and K. Jacob, Shumagin seismic gap, Alaska peninsula: History of great earthquakes, tectonic setting, and evidence for high seismic potential, J. Geophys. Res., 86, 3821-3855, 1981.

Dmowska, R., and L. C. Lovison, Influence of asperities along subduction interfaces on the stressing and seismicity of the adjacent areas, Tectonophysics, 211, 23-43, 1992.

Ekstrom, G., and E. R. Engdahl, Earthquake source parameters and stress distribution in Adak Island region of the central Aleutian Islands, Alaska, J. Geophys. Res., 94, 15,499-15,519, 1989.

Engdahl, E. R., J. W. Dewey, and S. Billington, Evidence for contortion of the subducted plate in the central Aleutians (abstract), Eos Trans. $A G U, 63,439,1982$.

Erickson, B. H., F. P. Naugler, and W. H. Lucas, Emperor fracture zone: A newly discovered feature in central North Pacific, Nature, 225, 53-54, 1970.

Estabrook, C. H., and K. H. Jacob, Stress indicators in Alaska, in Decade Map, Vol. 1, Neotectonics of North 
America, edited by D. B. Slemmons, E. R. Engdahl, N. D. Zoback, and D. D. Blackwell, pp. 387-399, Geol. Soc. of Am., Boulder, Colo., 1991.

Gates, O., and W. Gibson, Interpretation of the configuration of the Aleutian arc, Geol. Soc. Am. Bull., 67, 127-146, 1965.

Geist, E. L., J. R. Childs, and D. W. Scholl, The origin of summit basins of the Aleutian Ridge: Implications for block rotation of an arc massif, Tectonics, 7, 327-341, 1988.

Gephart, J. W., FMSI: A FORTRAN program for inverting fault/slickenside and earthquake focal mechanism data to obtain the original stress tensor, Comput. and Geosci., 16, 953-989, 1990.

Gephart, J. W., and D. W. Forsyth, An improved method of determining the regional stress tensor using the earthquake focal mechanism data: Application to the San Fernando earthquake sequence, $J$. Geophys. Res., 89, 93059320, 1984.

Gillard, D., and M. Wyss, Comparison of strain and stress tensor orientation: Application to Iran and southern California, J. Geophys. Res., in press, 1995.

Grim, P. J., and B. H. Erickson, Fracture zones and magnetic anomalies south of the Aleutian trench, J. Geophys. Res., 74, 1488-1494, 1969.

Hayes, D. E., and J. R. Heirtzler, Magnetic anomalies and their relation to the Aleutian Island Arc, J. Geophys. Res., 73, 4637-4646, 1968.

House, L. S., and K. H. Jacob, Earthquakes, plate subduction, and stress reversals in the eastern Aleutian arc, $J$. Geophys. Res., 88, 9347-9373, 1983.

Hudnut, K. W., and J. J. Taber, Transition from double to single Wadati-Benioff seismic zone in the Shumagin Islands, Alaska, Geophys. Res. Lett., 14, 143-146, 1987.

Hwang, L. J., and H. Kanamori, Of the May 7, 1986 Andreanof Islands earthquake source parameters, Geophys. Res. Lett., 13, 1426-1429, 1986.

Johnson, J. M., and K. Satake, Rupture extent of the 1938 Alaskan earthquake as inferred from tsunami waveforms, Geophys. Res. Lett., 21, 733-736, 1994.

Johnson, J. M., Y. Tanioka, L. J. Ruff, K. Satake, H. Kanamori, and L. R. Sykes, The 1957 Great Aleutian earthquake, Pure Appl. Geophys., 142, 3-28, 1994.

Kelleher, J., and W. McCann, Buoyant zones, great earthquakes, and unstable boundaries of subduction, $J$. Geophys. Res., 81, 4885-4896, 1976.

LaForge, R., and E. R. Engdahl, Tectonic implication of seismicity in the Adak Canyon region, central Aleutians, Bull. Seismol. Soc. Am., 69, 1515-1532, 1979.

Lonsdale, P., Paleogene history of the Kula plate: Offshore evidence and onshore implications, Geol. Soc. Am. Bull., 100, 733-754, 1988.

Lu, Z., M. Wyss, and S. Wiemer, Recent seismicity in and around the Shumagin-Unalaska seismic gap, Alaska (abstract), Seismol. Res. Lett., 65, 33, 1994.

McKenzie, D. P., The relationship between fault plane solutions for earthquakes and the directions of the principal stresses, Bull. Seismol. Soc. Am., 59, 591-601, 1969.

Michael, A. J., Use of focal mechanisms to determine stress: A control study, J. Geophys. Res., 92, 357-368, 1987.

Mogi, K., Relationship between the occurrence of great earthquakes and tectonic structures, Bull. Earthquake Res. Inst. Univ. Tokyo, 47, 429-451, 1969.

Nakamura, K., and S. Uyeda, Stress gradient in arc-back arc regions and plate subduction, J. Geophys. Res., 85, 6419-6428, 1980.

Nakamura, K., K. H. Jacob, and J. N. Davies, Volcanoes as possible indicators of tectonic stress orientation - Aleu- tians and Alaska, Pure Appl. Geophys., 115, 87-112, 1977.

Naugler, F. P., and J. M. Wageman, Gulf of Alaska: Magnetic anomalies, fracture zones, and plate interactions, Geol. Soc. Am. Bull., 84, 1575-1584, 1973.

Newberry, J. T., D. L. Laclair, and K. Fujita, Seismolicity and tectonics of the far western Aleutian Islands, $J$. Geodynamics, 6, 13-32, 1986.

Nishenko, S. P., and K. H. Jacob, Seismolic potential of the Queen Charlotte-Alaska-Aleutian seismic zone, J. Geophys. Res., 95, 2511-2532, 1990.

Nishenko, S. P., and W. R. McCann, Seismolic potential for the world's major plate boundaries, in Earthquake Prediction-An International Review, Maurice Ewing Ser., Vol. 4, edited by D. W. Simpson, and P. G. Richards, pp. 20-28, AGU, Washington, D.C., 1981.

Owen, H. G., Atlas of Continental Displacement, $200 \mathrm{Mil}$ lion Years to the Present, 159 pp., Cambridge Univ. Press, New York, 1983.

Perry, R. B., and H. Nichols, Bathymetry of Adak canyon, Aleutian arc, Alaska, Bull. Geol. Soc. Am., 76, 365-370, 1965.

Rea, D. K., and J. M. Dixon, Late cretaceous and Paleogene tectonic evolution of the north Pacific Ocean, Earth Planet. Sci. Lett., 64, 67-73, 1983.

Ruff, L., and H. Kanamori, The rupture process and asperity distribution of three great earthquakes from long-period diffracted P-waves, Phys. Earth Planet. Inter., 31, 202230, 1983.

Ryan, H. F., and D. W. Scholl, Geological implications of great interplate earthquakes along the Aleutian arc, $J$. Geophys. Res., 98, 22,135-22,146, 1993.

Spence, W., The Aleutian arc: Tectonic blocks, episodic subduction, strain diffusion, and magma generation, $J$. Geophys. Res., 82, 213-230, 1977.

Stauder, W., Mechanism of the Rat Island earthquake sequence of February 4, 1965, with relation to island arcs and sea-floor spreading, J. Geophys. Res., 73, 3847-3858, 1968a.

Stauder, W., Tensional character of earthquakes foci beneath the Aleutian trench with relation to sea-floor spreading, J. Geophys. Res., 73, 7693-7701, 1968b.

Stauder, W., Fault motion and spatially bounded character of the earthquakes in Amchitka Pass and the Delarof Islands, J. Geophys. Res., 77, 2072-2080, 1972.

Stauder, W., and G. A. Bollinger, The focal mechanism of the Alaska earthquake of March 28, 1964, and of its aftershock sequence, J. Geophys. Res., 71, 5283-5296, 1966.

Stauder, W., and A. Udias, S-wave studies of earthquakes of the North Pacific, II, Aleutian Islands, Bull. Seismol. Soc. $A m ., 53,59-77,1963$.

Sykes, L. R., Aftershock zones of great earthquakes, seismicity gaps, and earthquake prediction for Alaska and Aleutians, J. Geophys. Res., 76, 8021-8041, 1971.

Taber, J. J., S. Billington, and E. R. Engdahl, Seismolicity of Aleutian Arc, in Decade Map, Vol. 1, Neotectonics of North America, edited by D. B. Slem mons, E. R. Engdahl, N. D. Zoback, and D. D. Blackwell, pp. 29-45, Geol. Soc. of Am. , Boulder, Colo., 1991.

Tichelaar, B. W., and L. Ruff, Depth of seismic coupling along the Aleutian zones, J. Geophys. Res., 98, 20172037, 1993.

Vogt, P. R., A. Lowrie, D. R. Bracey, and R. N. Hey, Subduction of aseismic oceanic ridges: Effects on shape, seismicity and other characteristics of the consuming plate boundaries, Spec. Pap. Geol. Soc. Am., 172, 1-59, 1976.

Wyss, M., and Z. Lu, Plate boundary segmentation by stress directions: Southern San Andreas fault, California, Geophys. Res. Lett., 22, 547-550, 1995. 
Wyss, M., B. Liang, W. R. Tanigawa, and X. Wu, Comparison of orientations of stress and strain tensors based on fault plane solutions in Kaoiki Hawaii, J. Geophys. Res., 97, 4769-4790, 1992.

Yoshida, S., Waveform inversion for rupture using a non-flat seafloor model: Application to 1986 Andrean of Islands and 1985 Chile earthquakes, Tectonophysics, 211, 45-59, 1992.
Z. Lu and M. Wyss, Geophysical Institute, University of Alaska, Fairbanks, Fairbanks, AK 99775. (e-mail: lu@giseis.alaska.edu)

(Received November 21, 1994; revised September 25, 1995; accepted September 29, 1995.) 